\title{
Increased liver tests and hepatomegaly: Is there an increased prevalence of Gaucher disease in this population?
}

\author{
Elkilic $\mathrm{O}^{1 *}$, Laeremans $\mathrm{H}^{2}$, Lasser $\mathrm{L}^{1}$ and Mboti $\mathrm{F}^{2}$ \\ ${ }^{1}$ Department of Gastroenterology, CHU-Brugmann, Brussels, Belgium \\ ${ }^{2}$ Newborn screening center-ULB, CHU-Brugmann, Brussels, Belgium
}

\section{Introduction}

Gaucher's disease is an autosomal recessive disorder, characterized by decreased levels of the lysosomal enzyme glucocerebrosidase. This deficiency results in a decreased breakdown of the glycosphingolipid glucocerebroside, which accumulates in the lysosomes of the monocytemacrophage system $[1,2]$.

The phenotype of Gaucher disease represent a continuum which ranges from a few signs or laboratory manifestations to the most severe congenital Gaucher disease [3].

Gaucher's disease is the most common form of sphingolipidosis. The incidence varies between $1 / 40.000$ in Central Europe [4] and $1 / 2.000$ in some non-European countries, such as Israel $[5,6]$.

The number of patients identified in Belgium indicates that the disease may be under diagnosed.

\section{Methods}

We started a screening, single center, study in our department in Brussels between 2011 and 2017. The inclusion criteria were unexplained liver enzymes, hepato- or splenomegaly, unexplained anemia (pancytopenia) or bone lesions without a known cause. The patients were excluded out the study if there was a diagnosis explaining these inclusion criteria, before, during or soon after the first visit.

The screening was performed using a dried bloodspot on Whatman paper 906. The enzymes were measured with a LC-MS-MS method according to the protocol of CDC (Centre of disease control and prevention). The method was validated for stability of the enzymes in the dried blood spot and variability. All runs were controlled with external controls from CDC and blanc correction was adapted. Cut-off values were $3 \mathrm{umol} / \mathrm{l} / \mathrm{h}$ has been proposed and used by the reference center.

Routine blood analyses were performed to find any cause who can explain a possible liver disease. The work-out was completed by imaging of the upper abdomen (ultrasound, CT or MRI). Most of the patient underwent a fibro scan to measure the degree of the fibrosis, this was not possible during the first two years of the study in our hospital. The patient underwent a biopsy of the liver in absence a diagnosis with high grade of fibrosis (F3F4) and if the liver enzymes were more than ten times the normal values.

\section{Ethical considerations}

The ethical committee of C.HU BRUGMANN, in Brussels granted ethical approval. All participants gave written informed consent.

\section{Results}

We selected 50 patients, 20 man and 30 females. The mean age was 48,34 years. Most of the patients showed elevation of the liver enzymes, 44 of 50 or $89 \%$ of the patients. This was associated with or without hepatosplenomegaly. One patient was screened for Gaucher disease because osteonecrosis with unknown origin but with elevated liver enzymes and hepatomegaly. None of the patients was screened positive for the disease of Gaucher.

A posteriori 42 patients was diagnosed with NAFLD, $3 \mathrm{NASH}$, 1 cirrhosis on alcoholic basis, 1 patient with elevated on alcohol consumption without cirrhosis, 1 chronic cholecystitis, 1 patient drug induced liver disease, 1 patient remained without a diagnosis.

The stage of fibrosis was preferment by fibro scan and 3 patients underwent a percutaneous liver biopsy, none of them showed Gaucher cells. Remarkably most of the patients had some degree of fibrosis: 9 (18\%) (patients with fibrosis grade F0F1 and 13 (26\%) grade F1. Two patients had even fibrosis stage F4, cirrhosis (NASH) (Tables 1, 2 and Figure 1).

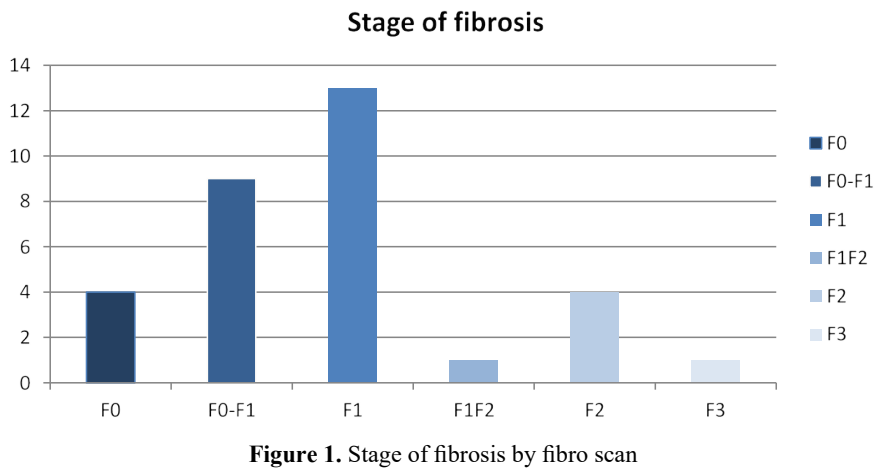

Table 1. Reason of screening for Gaucher disease

\begin{tabular}{|c|c|c|c|c|c|}
\hline $\mathbf{N}$ & Sex & Age (mean) & $\begin{array}{c}\text { Liver } \\
\text { enzymes }\end{array}$ & Hepatomegaly & Splenomegaly \\
\hline \multirow{2}{*}{50} & M: 20 & $48.3 \mathrm{y}$ & $45(90 \%)$ & $13(26 \%)$ & $6(12 \%)$ \\
\cline { 2 - 5 } & F: 30 & & & \\
\hline
\end{tabular}

${ }^{*}$ Correspondence to: Okyay Elkilic, Department of Gastroenterology, CHU Brugmann, Brussels, Belgium, Tel: +320-2477-2620; E-mail: okyay.ELKILIC@ chu-brugmann.be

Received: January 21, 2019; Accepted: February 08, 2019; Published: February 13,2019 
Table 2. Stage of fibrosis: determination of 36 patients, 3 by liver biopsy's, 33 by fibroscan

\begin{tabular}{|c|c|c|c|c|c|c|c|}
\hline F0 & F0-F1 & F1 & F1F2 & F2 & F3 & F3F4 & F4 \\
\hline 4 & 8 & 13 & 1 & 3 & 1 & 4 & 2 \\
\hline
\end{tabular}

\section{Discussion and conclusion}

In Belgium there are about 30 patients known with Gaucher disease, according to the literature finding [1], there must be more patients known with Gaucher disease among Belgium population. Despite this finding our small study is unable to show this revelation. None of the patients were detected with Gaucher disease.

This is a small study, maybe because of the severe inclusion criteria, patients were excluded if there was a clear cause of elevated liver enzymes, hepato- or splenomegaly.

Gaucher disease is very rare and seems to be difficult to detect surely in patients without advanced Gaucher disease.

Our patients were mainly selected in our department of hepatology based on elevated liver enzymes, initially without a clear diagnosis. Most of them seems to have a NAFLD. We propose to continue the screening and to recruit the patients from other disciplines such as hematology, rheumatology and neurology to have a larger study population and to increase de change of a positive screening.

\section{References}

1. Beutler E, Grabowski GA (2001) Gaucher disease. ( $8^{\text {th }}$ edn), New York: Mc Graw-Hill: 3635-3668.

2. Brady RO, Kanfer JN, Bradley RM, Shapiro D (1966) Demonstration of a deficiency of glucocerebrosidase-cleaving enzyme in Gaucher's disease. J Clin Invest 45: 11121115. [Crossref]

3. Dreborg S, Erikson A, Hagberg B (1980) Gucher disease-Norrbottnian type I. General clinical description. Eur JPed 133: 107-118. [Crossref]

4. Belgian expert opinion for diagnosis, treatment and monitoring of Gaucher's disease Available from: https://cema.uza.be/static/documenten/informatie_metabole_ziekten/ Belgian\%20Expert\%20Opinion\%20for\%20Diagnosis,\%20Treatment\%20an\%20 Monitoring\% $20 \mathrm{of} \% 20 \mathrm{Gaucher} . \mathrm{pdf}$

5. Goldblatt J (1988) Type I Gaucher disease. J Med Genet 25: 415-418. [Crossref]

6. Zimran A, Gelbart T, Westwood B, Grabowski GA, Beutler E (1991) High frequency of the Gaucher disease mutation at nucleotide 1226 among Ashkenazi Jews. Am J Hum Genet 49: 855-859. [Crossref]

Copyright: (C2019 Elkilic O. This is an open-access article distributed under the terms of the Creative Commons Attribution License, which permits unrestricted use, distribution, and reproduction in any medium, provided the original author and source are credited. 